\title{
To Remain Relevant, Change Agents Also Need to Change
}

\section{Danny A. Klinefelter}

Thank you for honoring me with the SAEA Lifetime Achievement Award. In reviewing the list of past participants as well as the credentials of this year's other recipients, I am very pleased to be included among them.

For more than 35 years I have carried a quote in my wallet that says, "The purpose of life is to count, to matter, to have it make some difference that you lived at all." I believe that the mission of both teaching and extension is to do exactly that.

Unfortunately, even successful individuals and organizations have a natural tendency to fall into the trap of focusing on what has worked well in the past, what they feel comfortable doing, and what is politically correct or politically expedient. The result is that we often stifle our role as change agents.

To remain effective and relevant, however, even change agents must make changes-in themselves. If universities and extension are to continue to serve as change agents in society today, we ourselves must embrace changes at many levels.

My career has focused on working as a teacher and in or with industry. Although I have a deep appreciation and respect for research, I limit my comments here to two areas wherein I can speak from experience: teaching and extension. My recommendations are based on four underlying principles:

- The only truly sustainable competitive ad-

Danny A. Klinefelter is professor and extension economist in the Department of Agricultural Economics, Texas A\&M University. vantage in any endeavor is the ability to learn and adapt faster than your competition.

- The best organizations spend as much time analyzing what they need to stop doing as they do evaluating new opportunities.

- To remain successful, we need to be learning organizations. This means that all members of the organization need to recognize that someone, somewhere, has a better idea or way of doing things, and they need to be compelled to find it, learn it, adapt it, and continually improve it.

- When the rate of change inside an organization becomes slower than the rate of change outside, its end is in sight. The only question is when.

These principles underlie the need for changes in five areas: a greater emphasis on alternative delivery and funding mechanisms; the development of new sources of funding for extension programming; an increased commitment to the economic principle of equal marginal returns; a shift in extension's management focus to become more strategic and entrepreneurial and less operational; and increased sharing of resources across state lines.

The first change relates to teaching, particularly at the graduate level. But it also applies to the continuing education needs of the faculty. Universities must look for new ways to offer relevant information in an increasingly wide range of subject areas. No university has all the expertise on staff to address every special topic or emerging area. Like successful businesses, universities need to build on their strengths and compensate for their weakness- 
es. They need to access the best talent available, wherever it resides.

For many years, sabbaticals have been used both to address the needs of universities for new ideas and expertise and for faculty members' continuing education. Sabbaticals are valuable, but they are often impractical if they involve uprooting a spouse from a job, renting out a home for a year, and disrupting schoolage children's lives.

Two practical and economical ways for universities to overcome their shortcomings are outsourcing and alliances. These can be facilitated by two-way interactive audio-video technology, which has improved dramatically in recent years.

This technology offers us flexibility, diversity in course offerings, and cost savings. For the cost of one faculty position, including benefits, this technology could enable a department to offer from four to six courses a year and to have the flexibility to shift resources as needs change. This is almost impossible to do with full-time faculty positions. The use of this technology could also save the time and expense of travel and temporary relocations if the "visiting" professors did not have to leave their own campuses. In some cases, it would be possible to teach an on-campus and a remote-access course simultaneously.

My second concern is that if extension becomes more dependent on state and local funding sources, programming will become more parochial and myopic as the funding sources demand that time and resources be devoted/restricted to local issues and problems. Unfortunately, an excessively local focus often engenders:

- A firefighting mentality driven more by political than by market forces.

- A tendency to focus more on symptoms than on the underlying causes of problems.

- Increasing focus on preserving the status quo and less focus on following the principle of comparative advantage and the strategic adjustment process.

- A tendency to avoid addressing politically sensitive issues.

- An underemphasis on programs that require a critical mass that frequently exceeds the number that would participate from a limited geographic area.

If extension economists believe that part of their mission includes programs that focus on strategic management, innovation, and policy analysis, we must place greater emphasis on alternative delivery and funding mechanisms. If not, we will increasingly be limited to awareness and social service programs, while the most progressive and change-oriented clientele will continue the trend toward looking elsewhere to meet their needs.

The opportunities are unlimited if we can break some of our bonds of tradition and be allowed to pursue them:

- Webinar technology can take live and archived programming directly into individual homes and offices.

- Fee-based programs could be set up more for cost recovery or even revenue generation rather than the token pricing that typically occurs. If what we do truly has value to end users with the ability to pay, we need to recognize the possibilities by looking at private seminars, engineering extension programs, and business school management development programs.

- Grants, contracts, corporate sponsorships, and alliances with trade associations or government agencies are also possibilities.

- The marketing club concept and needs-based training could also be extended to management clubs and peer advisory groups. Both are already widely used with business entrepreneurs and closely-held businesses outside of agriculture.

The third change needed is for universities and extension to further embrace the economic principle of equal marginal returns. We have often ignored this principle because it requires that we be proactive and continuously reallocate resources to their highest and best use. This principle also can conflict with tenurebased faculty, whether tenure is defined in academic or longevity terms.

Conflicting priorities can arise from differ- 
ing definitions of our market. If we view our primary market as the public sector-which is a fact of life for many administrators-we become political economists. If we view our market as the end user, we look at the world more as market economists. Extension needs to be managed and structured to encourage and reward both. As one who is more marketdriven, I believe it is clear that we need to develop new delivery methods, alternative funding sources, and programs that develop strong private-sector advocates and alliances.

This in no way implies that extension should abandon its traditional clientele. However, as the economy, the industry, and the world continue to change, we need to capitalize on the opportunities in continuing education and training using approaches employed by the more progressive business schools and engineering extension programs, which agricultural extension has often ignored or treated as some form of heresy. Review the four principles I stated at the outset. The issue is whether extension administrators can or will support a bifurcated delivery and funding structure.

The fourth change that I recommend is a change in extension's management focus. In many states, budget and staff cutbacks have severely restricted extension's ability to provide traditional programs and services. However, these same pressures also create opportunities for innovation and alternative approaches. I believe that extension needs to become more strategic and entrepreneurial and less operational in its management focus. Many businesses and organizations have failed because they were doing something very well but were no longer relevant or what the market was rewarding.

It is important to recognize that the market is not just those people or groups we have always served or are now serving. It also includes potential and emerging market segments, which may be even larger than some of our current clientele segments.

Because most extension programming falls under the umbrella of a public good, our programs must be accessible to and reach as many people as possible. But if we are really interested in changing behavior and having an economic impact, it is equally important that we recognize the reality of the 80:20 rule. Every person is just as important as every other, but people's needs often differ. Businesses and politicians both learned long ago that, however politically incorrect it may sound, it is as important to reach those who count as it is to count those they reach.

Translated into extension terms, economic impact should be as important as head counts. My experience has shown that changing the knowledge and behavior of the innovators and the leaders is often a more effective and faster way to have an impact than trying to effect change among those who are followers. There are more people who change only when they feel the heat than there are who change because they see the light.

In this same vein, extension could benefit from broadening the way it has traditionally originated and marketed its programs and services. Although the county agents have been and will continue to be the grassroots of the organization, there is an increasing need to market through multiple channels. Using the business analogy, the county agents are the local retail dealer network, but extension also needs to significantly expand its efforts in direct and wholesale marketing. Direct marketing includes more effective use of the Internet; demographically sorted and targeted mailings; more effective use of the trade press; and corporate, trade organization, and government agency partnerships and sponsorships.

Although private consulting should be handled as a consulting leave, and public employee endorsement and promotion of a private company's product or services may be a breach of public trust, I believe that extension faculty should be strongly encouraged to make presentations and conduct educational seminars for customer groups, company employees, and organizational members. This approach would provide a way to cover travel expenses and promotional costs, and it would enable us to leverage our resources to reach more people, many of whom are in a position to effect change and multiply our impact.

I would argue that people such as Mike Boehlje and Dave Kohl have reached and im- 
pacted more people than have traditional extension management economists, in part because of the information they have assimilated from observing and interacting with national and international audiences, in part from what they have learned from their consulting experiences, and in part because of their interaction with industry leaders and entrepreneurs. In addition to being exposed to a wider array of alternative approaches and ways of thinking, they also have gained a much better understanding of real-world implementation issues and impediments. They have learned from experience that if you can't communicate a message in a way that motivates your audience to act on it, having a message doesn't really matter.

Finally, I believe it is critical to extension's future that more programming be conducted on multicounty, statewide, multistate, national, and international levels. For certain market segments, programming opportunities at the county level are limited. Geographic and commodity boundaries are often limiting factors in reaching a sustainable critical mass and in stimulating new ideas. There is a tremendous need to develop ways to share resources across state lines, develop multistate or regional centers of excellence, and spend less time and resources reinventing the wheel.

For those of you who are accustomed to reading academic treatises and who feel that quotes and clichés evince a lack of scholarship and intellectual capacity, I apologize and hope you will pardon my rambling.

I'll conclude with an example I use with my undergraduate students that demonstrates the impact of and the need for change in order for a business to remain competitive. Two comments I hear frequently in my extension work are that most farmers and ranchers run their businesses more as producers than as business managers, and that they are resistant to change. From my experience, most farmers don't see either statement as being directly applicable to them personally. Most believe that they are managing their farms as businesses.

The question should really be: Are those farmers and ranchers using the best business management practices and do they possess the necessary management skills and attributes to compete with the best in the business? Almost all farmers also believe they have made significant changes in their businesses. Again, the real issue is: Are they moving forward as fast as their leading-edge competitors?

As an analogy, consider two people driving in the same direction on an interstate highway. Both are clearly changing-that is, they are moving forward. However, one is traveling 55 mph and the other $70 \mathrm{mph}$. If they both drive 8 hours a day, 5 days a week, at the end of 1 year the one going $70 \mathrm{mph}$ will be 31,200 miles ahead of the other.

But what if the 70-mph driver decided to ramp things up to do business $24 / 7 / 365$ ? If the $55 \mathrm{mph}$ driver stayed on his current pace, he would now be falling behind by 498,800 miles per year. Assuming the highway circumnavigated the earth, the slower driver would be getting lapped about 20 times a year.

Is this example extreme? Yes. Is it unrealistic? No. Large commercial dairies typically milk around the clock, 365 days a year. In another instance, a row crop operator I know now farms in 15 states so he can diversify production and market risks in addition to using his labor, management, and equipment 10 months a year rather than during the normal single-site planting and harvesting periods.

The point is that it is not just about the need to change for us to remain relevant, it is also about the extent and the speed of change. 